\title{
The Study on Repellent Activities of Four Kinds of Plant Essential Oils
}

\author{
DING Huipu ${ }^{1}$, LI Shuxin ${ }^{1}$, LIU Liping ${ }^{1 *}$, ZHANG Jie ${ }^{1}$ and XU $\mathbf{X u}^{2}$ \\ ${ }^{1}$ College of Biological \& Environmental Sciences, China \\ ${ }^{2}$ Ningbo Dayang Industry and Trade Co., Ltd, China \\ *Corresponding author: LIU Liping, College of Biological \& Environmental Sciences, Zhejiang Wanli University, Ningbo, 315100, \\ China
}

\begin{abstract}
Objective: To evaluate the mosquito repelling effects of four plant essential oils. Methods National standard method was adopted to test the mosquito repelling effects of four plant essential oils. Response surface methodology was used to analyze the optimum ratio of the essential oils.

Results: The repellent effects ranked as follows:

Chrysanthemum oil $>$ Calendula oil $>$ Holly oil $>$ Anise-star oil. And the synergistic effects were regarded with the combination of chrysanthemum and calendula oil. The mosquito repelling effect was up to $(93.33 \pm 2.57) \%$ when $50 \mu \mathrm{L}$ chrysanthemum oil and 18.49 $\mu \mathrm{L}$ calendula was mixed together in the $0.075 \mathrm{~m} 3$ cylinder.
\end{abstract}

Conclusion: The four plant essential oils all have good mosquito repelling effect and show synergism when they are mixed

Keywords: Plant essential oil; Mosquito repelling effect; Complex with; Synergism; Response Surface methodology

\section{Introduction}

Every spring and summer, the mosquito breeding speed increases, which brings great trouble to people's life and work. Not only it itches badly after the mosquito biting, but also it can spread malaria, dengue fever, yellow fever and other diseases [13]. In daily life, people will use a variety of mosquito repellents. Repellents are divided into chemical synthesis and plant source repellents. Among all these chemical syntheses, DEET has the most widely use [4,5]. But in recent years, Research have shown that DEET has a negative effect upon human body and is harmful to the environment. As the mosquitoes have been producing resistance to chemical repellents and the environmental pollution of chemical repellents has been worse [6]. People are paying more and more attention to environmentally friendly plant repellents [7]. Therefore, how to look for some new plant repellents taking place of DEET has become a hot topic.

Plants essential oils have the following advantages: low toxicity, without injury to the human body, environment-friendly and easily degradable. However, the repellency and permanence of plants essential oils are lower than synthetic repellents. Peppermint leaf and basil extracts have high repellent activity, but still below DEET's [8] \& Kwaka et al. [9] found that the protective rates on anopheles arabiensis mosquitoes of sweetscented basil leaf oil, african basil oil and DEET was respectively $91.98 \%, 89.75 \%$ and $93.40 \%$, and the protection rate of culex pipiens fatigans was $88.65 \%, 90.50 \%$ and $91.30 \%$. Weibin $\mathrm{M}$ [10] has studied the fumigation activity of holly essential oil against culex pipiens pallens. Holly essential oil had a good knockdown activity against culex pipiens pallens and KT50 was $3.91 \mathrm{~min}$ with $12 \mu \mathrm{L} / \mathrm{L}$ concentration.

Holly oil, chrysanthemum essential oil, calendula and star anise oil these four kinds was chosen and assessed the repellent against aedes albopictus for their broad source. The plant essential oils with good repellent ability were screened out by the combination of essential oils. It will provide experimental datum for finding natural mosquito repellent substances. 


\section{Experimental Materials and Instruments}

\section{Experimental material}

Plant essential oils: chrysanthemum essential oil, holly oil, calendula, star anise oil. The four plant essential oils were all extracted by steam distillation and should be stored in $\operatorname{cool} 4{ }^{\circ} \mathrm{C}$ and dark condition. All oils were provided by Ningbo Dayang Limited Company.

Test mosquitoes: Aedes albopictus female adults (3-4days old) were taken for the research. Larvae were reared at 12:12 light/ dark photoperiod, $70 \pm 2 \% \mathrm{RH}$, and $26^{\circ} \mathrm{C}$ in an insectary in Ningbo Dayang Limited Company.

\section{Experimental instrument}

Mosquito cage $(40 \mathrm{~cm} \times 30 \mathrm{~cm} \times 30 \mathrm{~cm})$, Cylinder (The cage is composed of three cages which diameter $25 \mathrm{~cm}$ and length $50 \mathrm{~cm}$. The three cylinders are separated by baffles). The fittings were all our own making.

\section{Experimental Method}

\section{Determination of mosquito repellent properties of essential oils[11]}

Determination of laboratory mosquitoes and workers: Using aggressivity experiment, 300 mosquitoes were placed in the mosquito cage. Experimenter (men and women are not limited. Don't drink alcohol, tea or coffee during the test and fragrance products are not used). The dorsum of the hand was exposed to a $40 \mathrm{~mm} \times 40 \mathrm{~mm}$ area and the rest of skins were sheltered closely. The experimenters extend their hands into the mosquito cage, shaking their hands to disperse the mosquitoes before the mosquito mouthparts pierce the skin, as 1 mosquito stop. The number of mosquitoes stopping on the skin during $2 \mathrm{~min}$ were observed. More than 30 mosquitoes were stopped, the experimenters and mosquitoes, attack was up to standard.

Determination of effective protection time: Four qualified experimenters (male and female were half each) were selected. Apply a certain amount of plant essential oils being tested to a hand which exposed to $40 \mathrm{~mm} \times 40 \mathrm{~mm}$ skin (closely masking the rest). After 5 minutes, put the experimenters' hands into the mosquito cage for 2 minutes. Observe whether it has any mosquitoes came landing frequency and blood feeding. Than the essential oils were tested every fifteen minutes after that. The essential oils were judged to invalid as long as a mosquito comes to suck blood. Record effective protection time(min) for plant essential oils repellents. The other hand was served as blank control.

Determination of repellent rate of compound plant essential oil: To select the essential oils with effectively repellent from "2.1.2", and use Optimal in Design-Expert 8.0.6 software to design compound experiment of essential oils of plant.100 female mosquitoes were placed in the middle cylinder of three $0.025 \mathrm{~m}^{3}$ cylinders (separated by baffles). Put the test oil in the other side of the cylinder. Two pieces of baffle between 3 cylinders are drawn at the same time in 2 minutes. Plug the bezel back in 10 minutes. Record the number of mosquitoes on both sides of the cylinder. Calculate the rate of essential oil repellent according to the following formula.

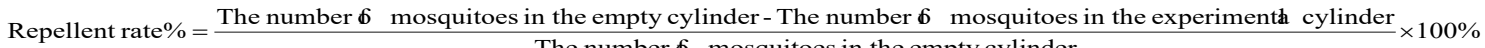

\section{Results}

The results of plant essential oil effective protection time

The effective time of four plant essential oils to repel mosquitoes: Four essential oils showed different repellent effects to Aedes albopictus. The repelling effectiveness time of the four essential oils ranked as follows: Chrysanthemum oil> Calendula> Holly oil> Anise-star oil. The repelling effectiveness time of chrysanthemum essential oil was up to 151.67 minutes (Table 1).
The repellent efficiency of mosquitoes to compound plant essential oil: According to the experimental results of four essential oils repellent effective protection time and considering the adaptation of essential oils aroma to the population. The essential oil of chrysanthemum and marigold was screened and compounded to test the rate of mosquito repellent. The results are shown in Table 2, 3 and Figure 1.

According to Table 3, the quadric polynomial fitting equations of the effect of plant essential oils on the rate of insect repellent was obtained.

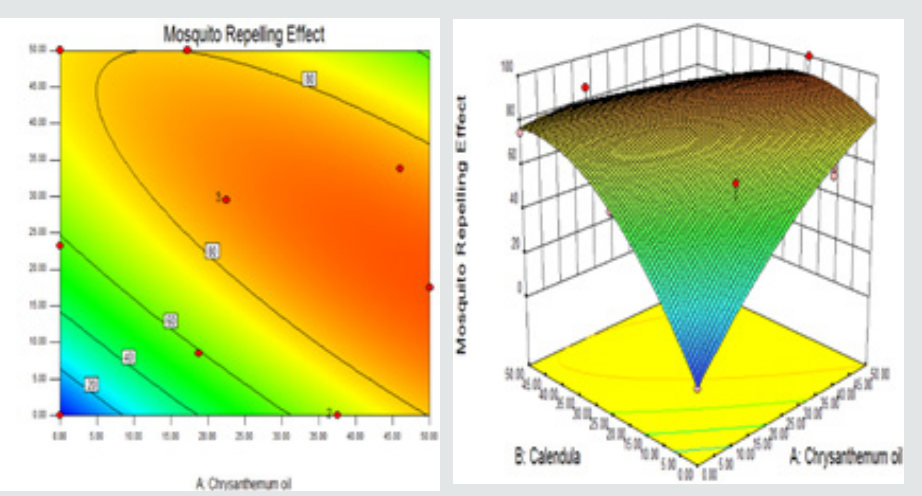

Figure 1: RSM analysis for interactive effects of chrysanthemum oils and calendula complexed 
Table 1: The effective protection time of mosquitoes on plant essential oils.

\begin{tabular}{|c|c|}
\hline Test Essential Oils & The Effective Protection time/min \\
\hline Holly oil & $94.00 \pm 3.74$ \\
\hline Chrysanthemum oil & $151.67 \pm 2.87$ \\
\hline Calendula & $119.33 \pm 3.30$ \\
\hline Anise-star oil & $90.00 \pm 4.08$ \\
\hline
\end{tabular}

Table 2: The experimental results of chrysanthemum oils and calendula complex.

\begin{tabular}{|c|c|c|}
\hline $\begin{array}{c}\text { Chrysanthemum } \\
\text { Oil/ } \boldsymbol{\mu L}\end{array}$ & Calendula/ $\boldsymbol{\mu L}$ & $\begin{array}{c}\text { Mosquito Repelling } \\
\text { Effect/\% }\end{array}$ \\
\hline 0 & 0 & 0 \\
\hline 22.5 & 29.5 & 85.7 \\
\hline 46 & 33.75 & 80 \\
\hline 22.5 & 29.5 & 86.3 \\
\hline 50 & 17.5 & 100 \\
\hline 0 & 50 & 75 \\
\hline 0 & 23.25 & 57.1 \\
\hline 37.5 & 0 & 66.7 \\
\hline 17.25 & 50 & 85.7 \\
\hline 18.75 & 8.5 & 66.7 \\
\hline 37.5 & 0 & 63.3 \\
\hline 22.5 & 29.5 & 81.4 \\
\hline
\end{tabular}

Table 3: ANOVA for response surface quadratic model analysis of variance table on chrysanthemum oils and calendula complex.

\begin{tabular}{|c|c|c|c|c|c|c|}
\hline Source & $\begin{array}{c}\text { Sum of } \\
\text { Squares }\end{array}$ & df & $\begin{array}{l}\text { Mean } \\
\text { Square }\end{array}$ & $\begin{array}{c}F \\
\text { value }\end{array}$ & $\begin{array}{l}\text { p-value } \\
\text { prob }>\text { F }\end{array}$ & $\begin{array}{c}\text { Signifi- } \\
\text { cance }\end{array}$ \\
\hline Model & 6792.05 & 5 & 1358.41 & 32.67 & 0.0003 & *** \\
\hline $\begin{array}{l}\text { A-Chrysan- } \\
\text { themum oil }\end{array}$ & 856.85 & 1 & 856.85 & 20.61 & 0.0039 & $* *$ \\
\hline $\begin{array}{l}\text { B-Calen- } \\
\text { dula }\end{array}$ & 667.34 & 1 & 667.34 & 16.05 & 0.0071 & $* *$ \\
\hline $\mathbf{A B}$ & 1050.15 & 1 & 1050.15 & 25.26 & 0.0024 & $* *$ \\
\hline $\mathbf{A}^{2}$ & 227.48 & 1 & 227.48 & 5.47 & 0.0579 & \\
\hline $\mathbf{B}^{2}$ & 801.17 & 1 & 801.17 & 19.27 & 0.0046 & $* *$ \\
\hline Residual & 249.46 & 6 & 41.58 & & & \\
\hline Lack of fit & 229.4 & 3 & 76.47 & 11.43 & 0.0378 & $*$ \\
\hline Pure Error & 20.07 & 3 & 6.69 & & & \\
\hline Cor Total & 7041.51 & 11 & & & & \\
\hline \multicolumn{7}{|c|}{ Note: ${ }^{*} \mathrm{P}<0.05,{ }^{* *} \mathrm{P}<0.01,{ }^{* * *} \mathrm{P}<0.001$} \\
\hline
\end{tabular}

The repellent rate $=85.91+15.05 \mathrm{~A}+13.51 \mathrm{~B}-24.76 \mathrm{AB}-10.44 \mathrm{~A}^{2}$ $21.57 \mathrm{~B}^{2}, \mathrm{R}^{2}=0.9646$

The result shows that the regression model $(\mathrm{P}<0.01)$ has very significant statistical significance. The two kinds of essential oils on the repellent rate have a significant impact (The $P$ value of $A 、 B 、 A B 、 B^{2}$ was less than 0.05 ). The influence sequence is as follows: Combination of chrysanthemum and marigold essential oil $\mathrm{AB}>$ Chrysanthemum oil $\mathrm{A}>$ Calendula oil B. From the experimental data and statistical analysis, there is obvious interaction between the two essential oils, compound essential oil repellent rate was significantly stronger than that of chrysanthemum and Calendula essential oil and the two essential oils have synergistic effect.

According to the analysis of the software, the mosquito repelling effect was $91.99 \%$ when $50 \mu \mathrm{L}$ chrysanthemum oil and $18.49 \mu \mathrm{L}$ calendula was mixed in the $0.075 \mathrm{~m}^{3}$ cylinder. Under this condition, three verification experiments were carried out. The average mosquito repelling rate was $93.33 \%$, the RSD was $2.57 \%(n=3)$. This result was close to the value predicted. It shows that the regression model has a certain prediction reliability.

\section{Discussion}

The research and development of plant essential oil repellent products cannot meet the current market demand. In this experiment, four essential oils were used to do mosquito repellent test on Aedes albopictus. The essential oils of Chrysanthemum oil, Calendula, Holly oil and Anise-star oil have repellent effects on Aedes albopictus. Among them, effects of chrysanthemum oil and Calendula repellent are good. The combination of the two has synergistic effect on mosquito repellent. Chrysanthemum and Calendula belong to the composite. They smell alike and are popular with the public. It has the potential to develop into a new generation of mosquito repellents and insect repellents. As a purely natural extract, it has an obvious advantage over chemically synthesized insecticides of the same kind.

\section{Conclusion}

The composition of essential oils is very complex. Now most of the studies focus on the use of plant essential oils as a whole or as a single ingredient in essential oils. However, there are few studies on the interaction between various components and essential oils. The synergistic effects between different essential oils and different active components need to be studied.

\section{Acknowledgements}

This work was supported by the 2019 Jiangbei District Agricultural and Social Development Science and Technology Plan Project in Ningbo City (2019C02), Zhejiang Province's Firstclass Discipline "Bioengineering" Student Innovation Program (CX2019028).

\section{References}

1. Fradin MS (1998) Mosquitoes and mosquito repellents: a clinician's guide. Ann Inter Med 128(11): 931-940. 
2. WHO (2015) New report signals country progress in the path to malaria elimination, Geneva, Switzerland.

3. Gillij YG, Gleiser RM, Zygadlo JA (2008) Mosquito repellent activity of essential oils of aromatic plants growing in Argentina. Bioresour Technol 99(7): 2507-2515

4. Jingjie X, Yanqiang Z, Fan Li (2013) New progress of mosquito repellents. Chinese Journal of vector biology and control 24(1): 79-82

5. Xiufang W, Linlin X, Kaiping X (2012) Research progress in plant control of mosquitoes. Anhui Agricultural Science 40(34): 16651-16654, 16747.

6. Gul S, Ibrahim S, Wasif N, Zafar A, Syed R (2013) Mosquito repellents: Killing mosquitoes or yourselves. Journal of Scientific and Innovative Research 2(6): 1052-1057.

7. Williams CR, Smith BPC, Best SM, Tyler MJ (2006) Mosquito repellents in frog skin. Biology letters 2(2): 242-245.
8. Lisa X, Ziqiang G, Yangwei O (2012) Comparison of chemical components of essential oil extracted from citronella by supercritical $\mathrm{CO}_{2}$ extraction and steam distillation. Anhui Agricultural Science 40(20): 10397-10398.

9. Kweka EJ, Mosha FW, Lowassa A, Mahande AM, Mahande MJ , et al. (2008) Longitudinal evaluation of Ocimum and other plants effects on the feeding behavioral response of mosquitoes (Diptera: Culicidae) in the filed in Tanzania. Parasit Vectors 1(1): 42.

10. Weibin M, Juntao F, Zhiqing M (2013) Bioactivity of Ilex oil and cinnamon oil against Culex pipiens pallens. Acta Entomology 56(12): 1391-1396

11.GB/T 13917.9-2009 (2009) Laboratory efficacy test and evaluation of hygienic insecticides for pesticide registration [S]. Beijing: China Standards Press, China, pp.24-28.
(C) This work is licensed under Creative

To Submit Your Article Click Here: Submit Article

DOI: $10.32474 /$ CTBM.2019.01.000116

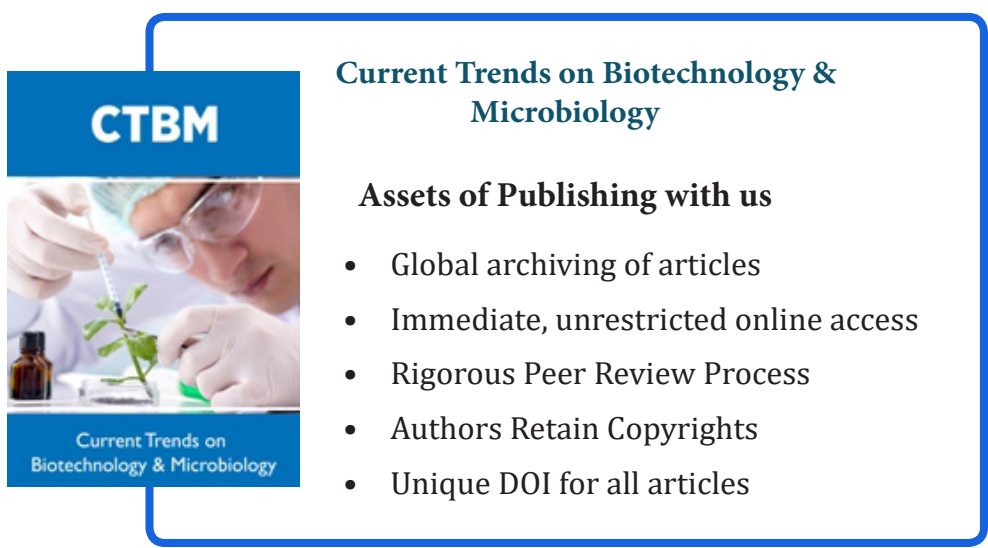

